\title{
Phytotoxicity: An Overview of the Physiological Responses of Plants Exposed to Fungicides
}

\author{
Maria Celeste Dias \\ Department of Biology \& Center for Environmental and Marine Studies (CESAM), University of Aveiro, 3810 Aveiro, Portugal \\ Correspondence should be addressed to Maria Celeste Dias, celeste.dias@ua.pt
}

Received 15 October 2011; Revised 5 January 2012; Accepted 26 January 2012

Academic Editor: Helena Oliveira

Copyright () 2012 Maria Celeste Dias. This is an open access article distributed under the Creative Commons Attribution License, which permits unrestricted use, distribution, and reproduction in any medium, provided the original work is properly cited.

In the last decades, the use of fungicides in agriculture for fungi diseases control has become crucial. Fungicide research has produced a diverse range of products with novel modes of action. However, the extensive use of these compounds in the agriculture system raises public concern because of the harmful potential of such substances in the environment and human health. Moreover, the phytotoxic effects of some fungicides are already recognized but little is known about the impact of these compounds on the photosynthetic apparatus. This paper presents a comprehensive overview of the literature considering different classes of fungicides and their effects on plant physiology, with particular emphasis on photosynthesis.

\section{Introduction}

Fungicides are chemical compounds or biological organisms that destroy or inhibit the growth of fungi or fungal spores [1]. The use of fungicides for an effective control of plant diseases has become crucial in the last decades in the agriculture system since it is estimated that fungal infections cause yield reductions of almost $20 \%$ of crops worldwide [1]. Due to their relatively low cost, ease of use, and effectiveness, fungicides became the primary means of fungi control [2]. However, the extensive use of these compounds to control fungal disease in plants raises the appearance of new strains of pathogens that have become resistant to the available commercial products [3].

Fungicide toxicity is not always restricted to the target pest organism, having also been demonstrated in mammals [4] including humans [5]. The extensive use of fungicides in plant protection against fungal disease generates longterm residues in food and in the environment $[6,7]$. In the annual EU report, EFSA (European Food Safety Authority), where vegetables and fruits of 27 countries were surveyed for pesticides contamination, the results highlighted that dithiocarbamates are among the most common residual contaminants. Thus, the abusive use of such compounds in agriculture has mobilized public concern because of the harmful potential of such substances in the environment and in the food chain representing a risk for human health [6].

Most of the work dealing with the impact of fungicides in agriculture is focused on their efficiency against fungal pathogens or their residues in crops $[6,8]$. Several reports appoint that some fungicides may enhance plant defences through phytoalexin synthesis and cell wall lignification or stimulate enzymes involved in the synthesis of phenolic compounds [8-10]. Others describe the putative protective role of fungicides for crops against various types of stress. Wu and Von Tiedemann [11] reported that triazoles protect Hordeum vulgare and Arachis hypogaea against ozone exposure or salt stress by stimulating antioxidative enzymes. Moreover, azoxystrobin and epoxiconazole fungicides induced a delay of senescence of Triticum aestivum mainly due to an enhancement of the antioxidative potential protecting the plants from harmful active oxygen species [11]. Muthukumarasamy and Panneerselvam [12] described an induction of the synthesis of photosynthetic pigments and proteins in fungicideexposed plants. However, few studies have addressed the question of whether these products alter or inhibit physiological and metabolic activities in the plant [3], and the negative effects of some fungicides on photosynthesis, pigment content, growth, and alterations in the reproductive organs were poorly explored $[7,8]$. The available data report 
modifications on the $\mathrm{CO}_{2}$ assimilation and photosynthetic efficiency [7, 8, 13-15]. Photosynthesis reduction strongly conditions biomass production and growth rates, which are strictly related with crop productivity and yield. Information on fungicides effects on plant physiology (photosynthesis) is crucial for the understanding of the underlying regulatory mechanisms as a precondition to judge the phytotoxicity of a compound. In this paper I present a comprehensive overview of the literature considering different classes of fungicides and their effects on plant physiology, with particular emphasis on photosynthesis. Finally, some general conclusions are drawn.

\section{Types of Fungicides}

Fungicides that are used to control plant fungi can be applied before infection to protect the plant from fungi invasion. This type of fungicides have a protective action. Others can be used to eliminate or eradicate an established infection. Fungicides can be classified in two main categories: contact (nonsystemic) and systemic fungicides.

2.1. Contact Fungicides. Contact fungicides have preventive action by killing or inhibiting fungi or fungal spores before the mycelia can grow and develop within the plant tissues [16]. However, once the infection is established, this fungicide may not have any function. Thus, this kind of fungicides can be used only as protectants.

Inorganic copper compounds such as Bordeaux mixture and copper carbonate and inorganic sulfur in the form of elemental sulfur and lime sulfur are some examples of the main contact fungicides available for plant protection [3]. Within the organic contact fungicides, for example, dialkyldithiocarbamates, which include the fungicides thiram, ferbam, and ziram, are a group of fungicides with a high role in the worldwide control of plant diseases since they are generally more effective and less toxic than the inorganic compounds (e.g., sulfur and copper fungicides) [4, 17]. These multisite inhibitors have several kinds of toxic action in fungal cells such as metal chelation, mixed disulfide formation, and transport of heavy metals across membranes. Dialkyldithiocarbamates inhibit a wide range of fungal enzymes, but the pyruvic dehydrogenase system is particularly sensitive to these fungicides [4]. Another group of organic contact fungicide widely used is the ethylenebisdithiocarbamates, which include zineb, maneb, metiram, and mancozeb. The mode of action of this type of fungicide differs from that of the dialkyldithiocarbamates: they undergo transformation to ethylenediisothiocyanate, which inactivates thiol groups of enzymes and metabolites in fungal cells.

Contact fungicides are inexpensive and fungal resistance rarely occurs. Therefore, they are still widely used for plant disease control even though many newer, more potent systemic fungicides have been developed

2.2. Systemic Fungicides. The other category of fungicides, systemic fungicides, are absorbed by the plant and carried by translocation to the site of infection. These kind of fungicides can kill the fungus after the mycelia has penetrated the parenchyma of the plant tissue, stopping the dispersal or infection within the plant [16]. Systemic fungicides can be used as protectants, eradicants, or both and are the most recently developed and the most promising type of fungicide for the future [3]. However, since systemic fungicides usually have a very specific site of action in the target fungus, fungi may readily develop resistance to them if they are not managed appropriately.

Systemic fungicides comprise a wide group of compounds with several modes of action. For example, the largest and most important group of systemic fungicides used to control plant fungal diseases is the dicarboximide. The mode of action of this fungicide seems to be related to the inhibition of triglyceride biosynthesis in the fungi [18]. The dicarboximide fungicides, iprodione, procymidone, vinclozolin, chlozolinate, and metomeclan are particularly valuable for the control of plant diseases caused by species of Botrytis, Sclerotinia, Monilinia, Alternaria, Sclerotium, and Phoma.

Benzimidazoles are a group of organic fungicides with systemic action that are also extensively used in agriculture. These types of compounds control a broad range of fungi at relatively low application rates [19]. For example, benomyl is one of the most effective and extensively used benzimidazoles in crop protection [3]. The benzimidazoles benomyl, carbendazim, and thiabendazole and the phenylcarbamate diethofencarb specifically interfere with the formation of microtubules, which function in a variety of cellular processes, including mitosis and maintenance of cell shape. These fungicides bind specifically to protein subunits called tubulin and prevent their assembly to form microtubules [20].

Since their introduction in the 1960s, systemic fungicides have gradually replaced the older nonsystemic products, establishing higher levels of disease control and developing new fungicide markets [1]. Compared with the nonsystemic, systemic fungicides are approximately twice as valuable in terms of sales [21].

\section{Plant Physiological Responses to Fungicide Exposure}

The widely accepted assumption that fungicide has low phytotoxicity has started to be outdated with the publication of more detailed analysis at the cell level that demonstrated several damages at the photosynthetic apparatus (e.g., [7, $8,15])$. Some reports appointed that application of fungicides has consequences on plant physiology, such as grow reduction, perturbation of reproductive organ development, alteration of nitrogen, and/or carbon metabolism [8]. This former physiological trait is fundamental for plant culture and is reflected by both photosynthetic rate and mobilization of carbohydrate reserves [7]. Physiological studies after fungicide application on several species reported modifications of both photosynthetic activity and chlorophyll $a$ fluorescence $[2,8,15,22,23]$. Decreased $\mathrm{CO}_{2}$ assimilation in fungicide-treated plants has been attributed to both stomatal (due to stomatal closure) [2] and nonstomatal effects due to 
a disruption in the capacity of RuBisCO carboxylation, decrease of RuBisCO content, and/or reduction of the ribulose 1.5 bisphosphate regeneration $[7,24]$.

Net $\mathrm{CO}_{2}$ assimilation reductions accompanied by changes in stomatal conductance and intercellular $\mathrm{CO}_{2}$ concentration were reported in Malus domestica and Cucumis sativus after fungicide application $[2,15]$. The application of a nonsystemic fungicide, fludioxonil, in Vitis vinifera induced a decrease in net $\mathrm{CO}_{2}$ assimilation and in the intercellular $\mathrm{CO}_{2}$ concentration but stomatal conductance was not affected [7]. In another study reported by Saladin et al. [8], the application of the same fungicide, fludioxonil, and a systemic fungicide, pyrimethanil, in in vitro plants and fruiting cuttings of Vitis vinifera promoted different physiological responses: in in vitro plants, both fungicides decreased net $\mathrm{CO}_{2}$ assimilation, transpiration rate, stomatal conductance, and intercellular $\mathrm{CO}_{2}$ concentration; in the fruiting cuttings, the fungicides did not affect $\mathrm{CO}_{2}$ exchange neither transpiration rates.

Some reports suggested that the systemic fungicide strobilurin may improve the water status and stress management of plants under conditions of drought stress $[25,26]$. Nason et al. [24] showed that the application of beta-methoxyacrylate, a strobilurin fungicide, improve the water use efficiency only in well-watered Triticum aestivum and Hordeum vulgare plants. However, when these plants are under drought stress, strobilurin strongly reduces net $\mathrm{CO}_{2}$ assimilation, intercellular $\mathrm{CO}_{2}$ concentration, transpiration rate, and rate of stomatal conductance to water. In this study, net $\mathrm{CO}_{2}$ assimilation reduction seems to be related to stomatal conductance decrease. It is possible that stomata respond to strobilurin-induced changes in mesophyll photosynthesis either by sensing changes in the intercellular $\mathrm{CO}_{2}$ concentration or by responding to the pool size of an unidentified C-fixing substrate. It is also possible that the effects of strobilurin fungicides are mediated via ABA-based chemical signaling [24].

The analysis of several chlorophyll $a$ fluorescence parameters of plants treated with fungicides $[2,15,22,23,27]$ demonstrated that light reactions of photosynthesis are also sensible to fungicide exposure. Bader and Abdel-Basset [27] showed, for the first time, that fungicides of the triforine type (a systemic and contact fungicide) strongly inhibit electrontransport reactions of chloroplasts. Moreover, the application of systemic fungicides, benzimidazoles and triazole, and a dithiocarbamate contact fungicide affected the effective quantum yield of PSII $\left(\Phi_{\text {PSII }}\right)$ as well as the maximal quantum efficiency of PSII $\left(F_{v} / F_{m}\right)$. This reduction was attributed to the decrease in photochemical quenching $(\mathrm{qP})$ $[2,15,23]$. In Glycine max, strobilurin fungicides application reduced the ratio of $F_{v} / F_{m}$ [24]. Strobilurin fungicides seem to block the transport of electrons between PSII and PSI by binding to the Qi site of the chloroplast cytochrome $b f$ complex [24].

Since plants depend on photosynthesis to assimilate carbon for further growth and overall vigor, photosynthesis impairment has negative consequences in plant biomass production and yield. Several reports support a decrease in biomass production in fungicides-treated plants: benomyl, a systemic fungicide, reduced the growth of Gossypium hirsutum, Helianthus annuus, Cucumis sativus, Lactuca sativa, and Pinus taeda $[3,13]$. Moreover, the application of carbendazim (systemic benzimidazole fungicide) in Nicotiana tabacum affected negatively plant biomass [3].

Pigment biosynthesis is appointed by Ahmed et al. [13] to be inhibited by the systemic fungicide, benomyl. This fungicide induces a considerable reduction on the chlorophyll $a$, chlorophyll $b$, carotenoids, and the total pigments content of Helianthus annuus plants [13]. Similarly, the treatment of Vitis vinifera with fludioxonil and Nicotiana tabacum with carbendazim also decreases the chlorophyll and carotenoid content [3, 8]. Mihuta-Grimm et al. [28] and Van Iersel and Bugbee [23] reported leaf chlorosis after benomyl application on Impatiens walleriana, Cucumis sativus, Celosia plumose, Petunia hybrid, and Lycopersicon esculentum.

Modifications of dark respiration were reported after mancozeb (contact fungicide) and flusilazol (systemic fungicide) application in Malus domestica [15]. The increase in dark respiration can be explained by additional energy requirement, metabolic breakdown of the compound, and/or activation of the alternative, cyanide-insensitive, respiration. Curiously, the treatment with strobilurin fungicides induced different responses: while in Triticum aestivum and in Spinacia oleracea plants respiration was inhibited [25, 29], in Triticum aestivum dark respiration was reduced [24].

\section{Conclusion}

The available studies in the literature have demonstrated that fungicide application impairs photosynthesis. However, the reports available are in general based on few physiological parameters using a large variety of plant species and different types of fungicide leading in some cases to controversial results that jeopardize a comprehensive knowledge of the main photosynthetic targets of fungicides. Thus, future investigation on the subject should be considered in order to produce more reliable data to identify fungicide photosynthetic targets and build a comprehensive model of the physiological response of plant exposed to fungicides.

It is expected that fungicides remain an essential tool for plant disease management and will continue to play a crucial role in optimizing yields from the world crops. Therefore, the development of new compounds with lower negative impact in plant physiology is a future challenge. This will provide benefits not only for plants yield but also for the environment and human health.

\section{Acknowledgment}

This work was supported by the Portuguese Foundation for Science and Technology (FCT) through a postdoctoral fellowship to M. C. Dias (SFRH/BPD/41700/2007).

\section{References}

[1] M. L. Gullino, P. Leroux, and C. M. Smith, "Uses and challenges of novel compounds for plant disease control," Crop Protection, vol. 19, no. 1, pp. 1-11, 2000. 
[2] X. J. Xia, Y. Y. Huang, L. Wang et al., "Pesticidesinduced depression of photosynthesis was alleviated by 24epibrassinolide pretreatment in Cucumis sativus L.," Pesticide Biochemistry and Physiology, vol. 86, no. 1, pp. 42-48, 2006.

[3] P. C. García, R. M. Rivero, J. M. Ruiz, and L. Romero, "The role of fungicides in the physiology of higher plants: implications for defense responses," Botanical Review, vol. 69, no. 2, pp. 162-172, 2003.

[4] F. Belpoggi, M. Soffritti, M. Guarino, L. Lambertini, D. Cevolani, and C. Maltoni, "Results of long-term experimental studies on the carcinogenicity of ethylenebis- dithiocarbamate (mancozeb) in rats," Annual New York Academic Science, vol. 982, pp. 123-136, 2002.

[5] C. A. C. Mendes, G. E. Mendes, J. P. Cipullo, and E. A. Burdmann, "Acute intoxication due to ingestion of vegetables contaminated with aldicarb," Clinical Toxicology, vol. 43, no. 2, pp. 117-118, 2005.

[6] European Food Safety Authority, "Annual report on pesticide residues," EFSA Scientific Report vol. 305, 2009.

[7] A. N. Petit, F. Fontaine, C. Clément, and N. Vaillant-Gaveau, "Photosynthesis limitations of grapevine after treatment with the fungicide fludioxonil," Journal of Agricultural and Food Chemistry, vol. 56, no. 15, pp. 6761-6767, 2008.

[8] G. Saladin, C. Magné, and C. Clément, "Effects of fludioxonil and pyrimethanil, two fungicides used against Botrytis cinerea, on carbohydrate physiology in Vitis vinifera L.," Pest Management Science, vol. 59, no. 10, pp. 1083-1092, 2003.

[9] J. P. Bryant, F. S. Chapin, and D. R. Klein, "Carbon/nutrient balance of boreal plants in relation to vertebrate herbivory," Oikos, vol. 40, no. 3, pp. 357-368, 1983.

[10] C. S. Awmack and S. R. Leather, "Host plant quality and fecundity in herbivorous insects," Annual Review of Entomology, vol. 47, pp. 817-844, 2002.

[11] Y. X. Wu and A. Von Tiedemann, "Impact of fungicides on active oxygen species and antioxidant enzymes in spring barley (Hordeum vulgare L.) exposed to ozone," Environmental Pollution, vol. 116, no. 1, pp. 37-47, 2002.

[12] M. Muthukumarasamy and R. Panneerselvam, "Amelioration of $\mathrm{NaCl}$ stress by triadimefon in peanut seedlings," Plant Growth Regulation, vol. 22, no. 3, pp. 157-162, 1997.

[13] A. M. Ahmed, M. D. Heikal, and O. S. Hindawy, "Side effects of benomyl (Fungicide) treatments on sunflower, cotton and cowpea plants," Phyton, vol. 23, pp. 185-195, 1983.

[14] R. Untiedt and M. Blanke, "Effects of fruit thinning agents on apple tree canopy photosynthesis and dark respiration," Plant Growth Regulation, vol. 35, no. 1, pp. 1-9, 2001.

[15] R. Untiedt and M. M. Blanke, "Effects of fungicide and insecticide mixtures on apple tree canopy photosynthesis, dark respiration and carbon economy," Crop Protection, vol. 23, no. 10, pp. 1001-1006, 2004.

[16] M. P. Yuste and J. Gostinear, Handbook of Agriculture, Marcel Dekker, New York, NY, USA, 1999.

[17] M. Hunsche, L. Damerow, M. Schmitz-Eiberger, and G. Noga, "Mancozeb wash-off from apple seedlings by simulated rainfall as affected by drying time of fungicide deposit and rain characteristics," Crop Protection, vol. 26, no. 5, pp. 768-774, 2007.

[18] L. G. Copping, "Review of major agrochemical classes and uses," in Chemistry and Technology of Agrochemical Foundations, D. A. Knowles, Ed., p. 29, Kluwer Academic Publishers, Dordrecht, The Netherlands, 1998.

[19] C. J. Delp, "Benzimidazole and related fungicides," in Modem Selective Fungicides: Properties, Applications, Mechanisms of
Action, H. Lyr, Ed., pp. 233-244, Wiley, New York, NY, USA, 1987.

[20] C. Tomlin, "The pesticide manual: a world compendium ," in Incorporating the Agrochemicals Handbook, Royal Society of Chemistry, England, UK, 1994.

[21] H. G. Hewitt, Fungicides in Crop Protection, CAB International, New York, NY, USA, 1998.

[22] B. W. Krugh and D. Miles, "Monitoring the effects of five "nonherbicidal" pesticide chemicals on terrestrial plants using chlorophyll fluorescence," Environmental Toxicology and Chemistry, vol. 15, no. 4, pp. 495-500, 1996.

[23] M. W. Van Iersel and B. Bugbee, "Phytotoxic effects of benzimidazole fungicides on bedding plants," Journal of the American Society for Horticultural Science, vol. 121, no. 6, pp. 1095-1102, 1996.

[24] M. A. Nason, J. Farrar, and D. Bartlett, "Strobilurin fungicides induce changes in photosynthetic gas exchange that do not improve water use efficiency of plants grown under conditions of water stress," Pest Management Science, vol. 63, no. 12, pp. 1191-1200, 2007.

[25] J. Glaab and W. M. Kaiser, "Increased nitrate reductase activity in leaf tissue after application of the fungicide Kresoximmethyl," Planta, vol. 207, no. 3, pp. 442-448, 1999.

[26] K. Grossmann, J. Kwiatkowski, and G. Caspar, "Regulation of phytohormone levels, leaf senescence and transpiration by the strobilurin kresoxim-methyl in wheat (Triticum aestivum)," Journal of Plant Physiology, vol. 154, no. 5-6, pp. 805-808, 1999.

[27] K. P. Bader and R. Abdel-Basset, "Adaptation of plants to anthropogenic and environmental stresses," in The Effects of Air Constituents and Plant-Protective Chemicals, M. Pessarakli, Ed., Handbook of Plant and Crop Stress, pp. 973-1010, Marcel Dekker, New York, NY, USA, 1999.

[28] L. Mihuta-Grimm, W. A. Erb, and R. C. Rowe, "Fusarium crown and root rot of tomato in greenhouse rock wool systems: sources of inoculum and disease management with benomyl," Plant Disease, vol. 74, pp. 996-1002, 1990.

[29] H. Köhle, K. Grossmann, G. Retzlaff, and A. Akers, "Physiological effects of the new fungicide Juwel on yield in cereals," Gesunde Pflanzen, vol. 49, no. 8, pp. 267-271, 1997. 

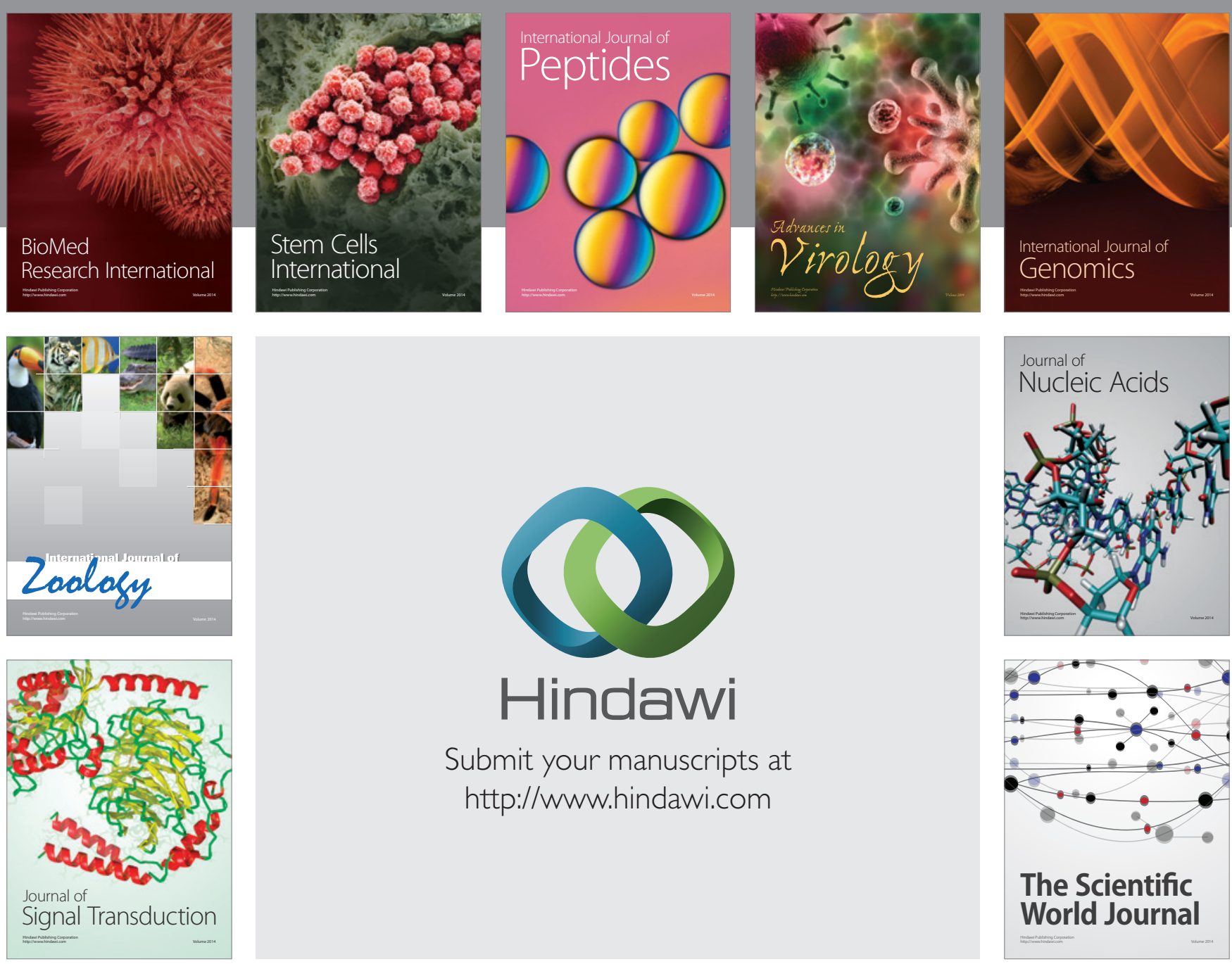

Submit your manuscripts at

http://www.hindawi.com
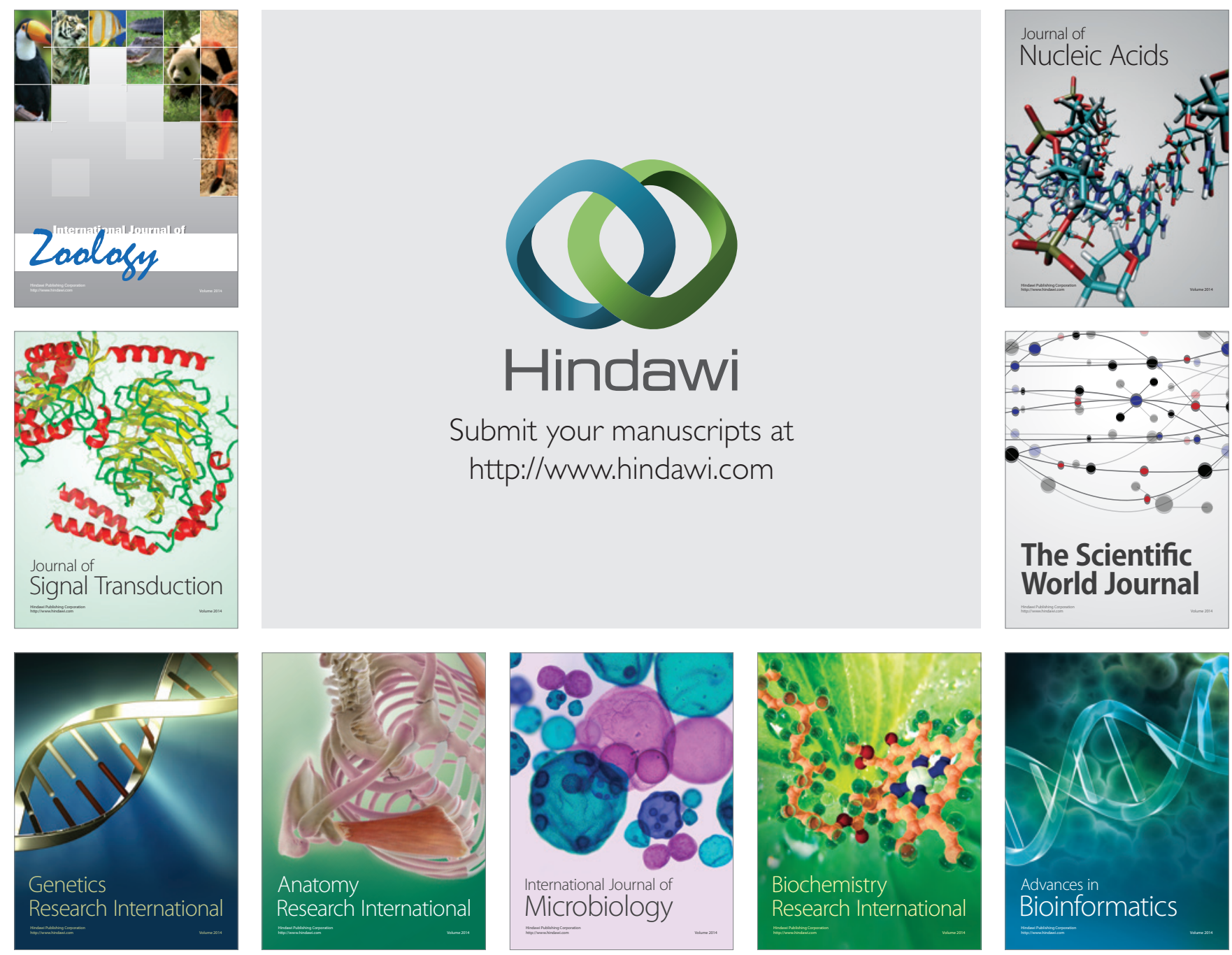

The Scientific World Journal
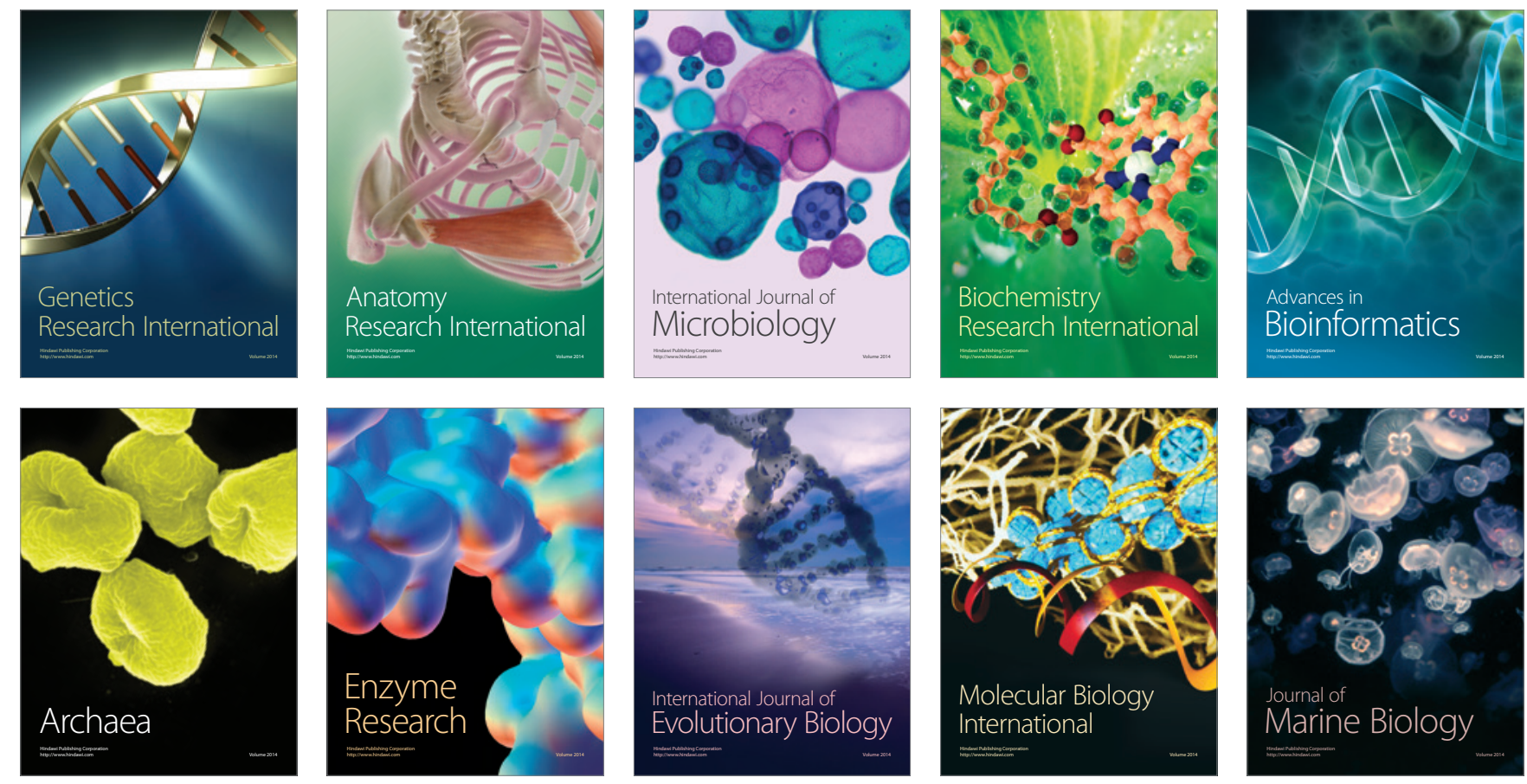